\title{
Where Are We Standing on Postpartum Care? A Cross-sectional Community Based Study
}

\section{Lohusa Bakımının Neresindeyiz? Kesitsel Tipte Toplum Tabanlı Bir}

\author{
Çalışma
}

\author{
Binali Çatak ${ }^{l}$, Can Öner ${ }^{* 2}$, Sevinç Sütlü̈, Selçuk Kılınç ${ }^{3}$
}

\begin{abstract}
Introduction: Postpartum care is one of the basic interventions to prevent complications that affect mother health. The aim of this study was to evaluate the postpartum care provided by primary health care in terms of quantity and content. Material and methods: Eight hundred sixteen women who gave birth between 1 June-31 August composed the universe of the study. The data was collected after official permissions and verbal consent of women participated in this study. Data collection form includes questions about sociodemographic and biodemographic characteristics of women and postpartum care. To determine the content of postpartum care 16parameters were determined from Postpartum Care Management Guideline. Data was analysed with SPSS 20 package program. Results: All women received postpartum care at least ones and $39.1 \%$ of women received more than three times. None of postpartum care parameters were applied to $1.0 \%$ and all of the 16 parameters were applied to $1.2 \%$ of puerperas. The most frequent parameters in the content postpartum care were breast feeding $(89.6 \%)$, maintaining iron supplement $(81.8 \%)$, blood pressure measurement $(80.2 \%)$ and education of mothers' nutrition $(76.1 \%)$. On the other hand, the least frequent parameters were perineal (4.7\%) and abdominal examination $(24.1 \%)$ and history taking about palpitations/shortness of breath $(28.0 \%)$. There was no significant difference between sociodemographic and biodemographic characteristics of women, parameters of healthcare usage and content of postpartum care ( $p>0.05$ ). Conclusion: All of the women had taken postpartum care, but the content was insufficient. Women's sociodemographic and biodemographic characteristics and features related to healthcare usage do not have effect on the content of postpartum care. In this context, family physicians and family midwives should be given reminder training according to Postpartum Care Management Guideline periodically.
\end{abstract}

Key words: Puerperium, puerperal care, postpartum care, primary care, family physician

\section{ÖZET}

Giriş: Lohusa bakımı, anne sağlığını etkileyecek komplikasyonların önlenmesinde temel müdahalelerden birisidir. Bu çalışmanın amacı, birinci basamak sağlık kurumları tarafından verilen lohusa bakımının, nicelik ve içerik açısından değerlendirilmesidir. Gereç ve Yöntem: Araştırmanın evrenini, Burdur'da 1 Haziran-31 Ağustos 2012 tarihleri arasında doğum yapmış 816 kadın oluşturmuştur. Veriler, gerekli izinler ve çalışmaya katılan kadınlardan sözlü onam alındıktan sonra toplanmıştır. Veri toplama formu, kadınların sosyodemografik, biyodemografik özellikleri ve lohusa bakımı ile ilgili soruları içermektedir. Lohusa bakım içeriğini belirlemek için, Doğum Sonrası Bakım Yönetim Rehberinden seçilen 16 parametre belirlenmiştir. Veriler, SPSS 20 paket programında analiz edilmiştir. Bulgular: Kadınların tamamı en az bir kez, \%39,1'i ise 3 ve daha fazla lohusa bakımı almıştır. Lohusaların, \%1,0'ine parametrelerden hiçbirisi, \%1,2'sine 16 parametrenin tamamı yapılmışıı. Lohusa bakım içeriğinde en fazla yer alan parametreler; emzirme $(\% 89,6)$, demir preparatı verilmesi $(\% 81,8)$, kan basıncı ölçümü $(\% 80,2)$ ve anne beslenmesi ile ilgili bilgi $(\% 76,1)$ verilmesidir. Öte yandan en az yer alan parametreler, perine muayenesi $(\% 4,7)$, karın muayenesi $(\% 24,1)$ ve çarpıntı/nefes darlığının olup olmadığının sorulmasıdır $(\% 28,0)$. Sosyodemografik, biyodemografik özellikler ve sağlık hizmeti kullanımına ilişkin değişkenler ile lohusa bakım içeriği arasında istatistiksel olarak anlamlı bir fark bulunmamıştır ( $>00,05)$. Sonuç: Araştırmada, kadınların tamamı lohusa bakımı almıștır fakat lohusa bakım içeriği yetersizdir. Kadınların sosyodemografik, biyodemografik ve sağlık hizmeti kullanımına ilișkin özellikleri lohusa bakım içeriği üzerinde etkili değildir. Bu bağlamda, Doğum Sonrası Bakım Yönetim Rehberinde belirtilen ilkeler doğrultusunda, aile hekimi ve aile sağlı̆̆ ebelerine periyodik olarak hatırlatma eğitimleri yapılmalıdır.

Anahtar kelimeler: Lohusa, lohusa bakımı, doğum sonrası bakım, birinci basamak, aile hekimi

Received / Geliş tarihi: 15.06.2017, Accepted / Kabul tarihi: 23.08.2017

${ }^{1}$ Kafkas Üniversitesi Tıp Fakültesi Halk Sağlığı Anabilim Dalı

${ }^{2}$ Dr Lütfi Kırdar Kartal EAH Aile Hekimliği Kliniği

${ }^{3}$ Burdur Halk Sağlığı Müdürlüğü

*Address for Correspondence / Yazışma Adresi: Can Öner, Dr Lütfi Kırdar Kartal EAH Aile Hekimliği Kliniği, Kartal, İstanbul-TÜRKIYYE, E-mail: trcanoner@yahoo.com

Çatak B, Öner C, Sütlü S, Kılınç S. Lohusa Bakımının Neresindeyiz? Kesitsel Tipte Toplum Tabanlı Bir Çalışma. TJFMPC, 2017; 11(4): 256264.

DOI: $10.21763 /$ tjfmpc.359817 


\section{GíRIŞ}

Dünya Sağlık Örgütü, doğum sonrası dönemi (lohusalık) plasenta ve eklerinin, anne rahminden ayrılmasını takip eden 1 saat ile doğumdan sonraki ilk 6 hafta (42 gün) olarak tanımlamıştır. ${ }^{1} \mathrm{Bu}$ dönemde, doğum sonrası oluşan kanamalar, enfeksiyonlar, komplikasyonlar ve depresyon nedeni ile anne sağlığı; asfiksi, enfeksiyonlar, anne sütü ile yetersiz beslenme ve bazı yanlış kültürel inanç ve uygulamalar nedeni ile yeni doğanların sağlığı olumsuz olarak etkilenmektedir., ${ }^{1,2}$ Anne ve bebek ölümlerinin önemli bir kısmı bu süre zarfında gerçekleşmektedir. $^{3}$

Yeterli bir doğum sonrası bakım hizmetinin, bebek ölümlerini antepartum ve intrapartum bakım hizmetlerine göre daha etkin ve düşük maliyetle azalttığ 1 gösterilmiştir. ${ }^{4}$ Bunun yanısıra, kadın sağlığı üzerine odaklanmış bir doğum sonrası bakım hizmetinin, kadınların fizyolojik ve psikolojik sağlığı üzerine olumlu etkileri olduğu bildirilmektedir. ${ }^{5}$ Doğum sonrası bakım hizmetleri, anne ve yeni doğanın sağlık sorunlarını belirlemek için sağlık çalışanlarına önemli bir imkan sağlamaktadır. ${ }^{6}$ Doğum sonrası bakım hizmetleri verilirken, emzirme, kişisel hijyen, aile planlaması gibi konularda eğitim verilerek, anne ve bebeğe postnatal demir, A ve $\mathrm{D}$ vitamini vs desteği sağlanarak anne ve bebeğin daha optimal sağlık hizmeti da sağlanabilir. ${ }^{7}$

Yapılan ulusal çalışmalarda, ölen annelerin \%25,0'inin ve neonatal ölümlerin yarısının doğum sırasında ve doğum sonrası ilk 24 saat içinde gerçekleştiği ve bu oranların doğumdan sonraki ilk haftanın sonunda sırasıyla \%60,0 ile üçte ikiye çıktığı bildirilmektedir. ${ }^{8}$ Dünya'nın birçok ülkesinde olduğu gibi, Türkiye'de de anne ölümleri için risk oluşturabilecek faktörler belirlenerek bu faktörlerin eliminasyonuna yönelik ulusal rehberler hazırlanmış ve uygulamaya koyulmuştur (Doğum Sonrası Bakım Yönetim Rehberi: DSB-YR). Bu rehberle birlikte, ülke genelinde doğum sonrası bakım standardize edilmiş ve yapılması gereken parametreler tanımlanmıştır. ${ }^{9}$ Türkiye Nüfus ve Sağlık Araştırması 2013 (TNSA-2013) verileri dikkate alındığında doğum sonrası bakım alanların oranı \% 93,2 olarak bildirilmektedir. 9 Türkiye'de doğum sonrası bakım hizmetlerinin kapsayıcılı̆̆ \% \%0'ların üzerine çıkmış olsa da, verilen hizmetin kalitesinin düşük olduğu bildirilmektedir. ${ }^{11,12}$

Sağlık politikasını oluşturanlar için güncellenmiş ulusal bilgiler, gelecekte doğum sonrası bakım hizmetlerinin kullanımının artması ve içeriğinin yeterli kılınması, ana ve çocuk ölümlerini azaltmaya yönelik önemli katkılar sağlayabilir. ${ }^{1}$ Sağlıkta Dönüşüm Programı kapsamında, 2005 yılından itibaren Türkiye'de birinci basamak sağlık hizmetlerinin örgütlenmesinde değişikliğe gidilmiş ve aile hekimliği uygulamasına geçilmiştir. $\mathrm{Bu}$ uygulama ile aile hekimleri kayitlı olan gebelerin doğum öncesi ve sonrasındaki bakım hizmetlerini ilgili kılavuzlara göre yapmakla görevlendirilmişlerdir. $\mathrm{Bu}$ k1lavuzda, lohusalara doğum sonrasında hastanede 3 ve taburculuk sonrası 3 olmak üzere, en az 6 lohusa bakımı verilmesi önerilmektedir. Yine, verilen bakım hikâye alınması, fizik muayene, laboratuvar hizmetleri, bilgilendirme- danışmanlık hizmetleri ve proflaksi hizmetlerini kapsamaktadır. ${ }^{9}$

$\mathrm{Bu}$ çalışma, aile hekimliği uygulaması sonrası, Türkiye'de doğum sonrası bakım hizmetlerinin kalitesini değerlendiren sayılı çalışmalardandır. Yine bu çalışma, 2 yıl ara ile aynı bölgede verilen doğum sonrası bakım hizmetlerinin kalitesini benzer yöntemlerle değerlendirmektedir ve bu açıdan aile hekimliğine geçişle beraber doğum sonrası bakımla ilgili hizmetlerin kalitesinin, ne yönde evrildiği konusunda fikir verebilir.

$\mathrm{Bu}$ çalışmanın temel amacı, birinci basamak sağlık kurumları (aile sağlığı birimleri) tarafından verilen doğum sonrası bakım hizmetlerinin, nicelik ve içerik açısından değerlendirilmesidir.

\section{YÖNTEM}

Çalışma, 1 Haziran - 30 Kasım 2012 tarihleri arasında Burdur ilinde yürütülmüştür. Çalışmanın hazırlık aşaması, 1 Haziran - 30 Ağustos 2012, veri toplama ve analiz kısmı ise 3 Eylül - 30 Kasım 2012 tarihleri arasında gerçekleşmiştir. Çalışmanın yapıldığ1 dönemde Burdur İl'inin toplam nüfusu 254.411'dir. Çalışmanın yürütüldüğü ilde, üçü kamu, biri özel sektöre ait olmak üzere toplam dört tane tam teşekküllü hastane ve 78 aile sağlı̆̆ birimi bulunmaktadır. Aile sağlığı birimi başına düşen nüfus yaklaşık olarak 3262 kişidir.

Aile sağlığı birimleri, azami 4000 nüfusa hizmet veren bir hekim ve aile sağlığı ebesinin oluşturduğu birimdir. Türkiye'de sağlıkta dönüşüm reformu kapsamında, 2005 yılından itibaren aile sağlığı merkezleri kurulmaya başlanmıştır. Bu sayede, birinci basamak sağlık hizmetleri tamamen aile hekimleri ve aile sağlığı ebesi tarafindan verilmeye başlanılmıştır. Aile hekimi ve aile sağlı̆̆ ebesi, kendilerine kayıtlı nüfusa birinci basamak 
iyileştirici, koruyucu ve rehabilite edici sağlık hizmetlerini vermekle ve verdiği bu hizmetleri Halk Sağlığı Müdürlüğü’ne bildirmekle yükümlüdür.

\section{Araştırmanın Tipi, Evreni ve Örneklemi}

Bu araştırmada, 'Burdur'da Doğum Sonrası Bakım Hizmetleri" adlı kesitsel tipteki alan araştırmasının "lohusa bakımı" ile ilgili kısmına ait veriler kullanılmıştır. Araştırmanın evrenini, 1 Haziran - 31 Ağustos 2012 tarihleri arasında doğum yapmış 816 kadın oluşturmuştur. Çalışmaya katılan tüm kadınlar lohusalık dönemlerini tamamlamışlardır. Araştırmada örneklem seçilmemiş olup, evrenin tümüne ulaşılması hedeflenmiştir. Görüşme yapıldığı sırada kadınların hepsi lohusalık dönemlerini tamamlamışlardı. Kadınların \%93,5'ine (763/816) ulaşılmıştır. Kadınlara ulaşamamanın en önemli nedenleri, kadının evde bulunamaması (19 kadın), çevre illerde (Antalya, Denizli, Isparta, vb.) yaşayan akrabalarının yanına gitmesi (28 kadın) ve il dışı kalıcı göçlerdir (6 kadın).

\section{Araştırmanın Değişkenleri}

Araştırmanın veri toplama formu, DSB-YR ve Türkiye Nüfus ve Sağlık Araştırması (TNSA) esas alınarak hazırlanmıştır. ${ }^{9,11}$ Veri toplama formu, kadinların sosyodemografik, biyodemografik özellikleri, lohusa bakımı, bebek bakımı ve bebeklerin sigara dumanından pasif etkilenimi ile ilgili sorulardan oluşturulmuştur. Formun "lohusa bakımı" ile ilgili kısmı, doğum sonu bakım yönetim rehberinde belirtilen ve lohusa izlemlerinde yapılması gereken parametreleri içeren sorulardan oluşturulmuştur.

Araştırmada lohusa bakımı; nicelik, içerik ve içeriği etkileyen faktörler açısından değerlendirilmiştir:

\section{1-Nicelik:}

Lohusanın, hastaneden taburcu olduktan sonraki 45 gün içinde, lohusa bakımı alıp almama durumu ve lohusa bakımı aldı ise kaç kez aldığı, bakımın niceliğini oluşturmuştur.

\section{2-İçerik:}

DSB-YR'de belirtilen her parametre anne sağlığ1 açısından vazgeçilmez öneme sahiptir. Bu nedenle lohusa bakımı, içerik olarak rehberde belirtilen tüm parametreleri içermelidir. Ancak çalışmada, rehberde belirtilen her parametrenin verilip verilmediğini sorgulamak araştırmayı yapılabilir olmaktan uzak kılacaktır. Dolayısı ile lohusa bakım içeriğini ölçülebilir hale getirmek için DSB-YR'de belirtilen öykü, fizik muayene, bilgilendirme/danışmanlık kısımlarının her birinden 5, ayrica proflaksi kısmindan (demir preparatı verilmesi) 1 olmak üzere toplam 16 parametre belirlenmiştir. ${ }^{9}$

İçerik için kullanılan parametreler şu şekilde belirlenmiştir; rehberde, hemoglobin ölçümü, idrar tetkiki gibi bazı parametrelerin "gerekiyorsa", vajinal smear gibi "özel eğitim gerektiren" durumların ise "tüm lohusalara" yapılması istenmektedir. ${ }^{9}$ Ancak, günlük pratiğimiz içinde tüm aile hekimi ve aile sağlı̆̆ smear alma, vajinal muayene yapma gibi konularda eğitimli olmadığı da bilinmektedir. Parametreler, tüm bu nedenler göz önüne alınarak, aile sağlığı birimi ve/veya ev koşullarında kolaylıkla yapılabilecekler arasından belirlenmiștir.

\section{Hikâyede sorulması istenen parametreler:}

Kanama, idrar yaparken yanma veya idrar kaçırma, sırt/göğüs/baş ağrısı, çarpıntı veya nefes darlığı, kabızlık şikâyetinin olup olmadığının sorulması

Fizik muayenede yapılması istenen parametreler:

Kan basıncı ve ateş ölçümü, nabız sayımı, karın ve perine muayenesinin yapılıp yapılmadığı

\section{Bilgilendirme/danışmanlıkta verilmesi istenen parametreler:}

Lohusalık döneminde, acilen sağlık kurumuna başvurmasını gerektiren durumlar, emzirme, aile planlamas1, meme bakımı ve uygun beslenme konusunda bilgi verilip verilmediği. ${ }^{9}$

\section{3-İçeriği etkileyen faktörler:}

Belirlenen her parametreye, yapılmışsa 1, yapılmamışsa 0 (sıfır) puan verilmiştir. Sonra puanlar toplanmış ve "lohusa bakım içerik puanı" oluşturulmuştur. Daha sonra lohusa bakım içerik puanına göre kadınlar, "5 ve daha az", "6-10" ve "11 ve üzeri” olmak üzere 3 gruba ayrılmıştır. Kadınların sosyodemografik, biyodemografik özellikleri ile sağlık hizmet kullanımına ilişkin özellikleri bağımsız, lohusa bakım içeriği puanları ise bağımlı değişken olarak alınarak bağımsız değişkenlerin bağımlı değişken üzerindeki etkileri değerlendirilmiştir. 


\section{Verilerin Toplanması}

Veriler, gerekli izinler alındıktan sonra, 3 Eylül - 30 Kasım 2012 tarihleri arasında toplum sağlığ1 merkezinde görev yapan ebe ve hemşireler tarafından toplanmıştır. Verileri toplamadan önce, standardizasyonu sağlamak için, veri toplayacak ebe ve hemşirelere eğitim programı hazırlanmıştır. Eğitim programı; çalışmanın amacı, hangi değişkenlerle ilgili bilgi toplanacağı ve veri toplama aşamasında dikkat edilmesi gereken durumları içermekteydi. Veri toplama formunun ön denemesi 2012 yılında doğum yapmış, ancak 1 Haziran-31 Ağustos tarihleri arasında doğum yapmamış ve il merkezinde yaşayan 7 kadın ile görüşülerek yapılmıştır. Toplanan formlar incelenmiş ve gerekli düzeltmeler yapılmıştır.

\section{Etik Onay Ve İzinler}

Veriler, Burdur Halk Sağlığı Müdürlüğü'nden gerekli izinler alındıktan sonra, 3 Eylül - 30 Kasım 2012 tarihleri arasında, toplum sağlığı merkezinde görev yapan ebe ve hemşireler tarafından, kadınlar sözlü onam alındıktan sonra yüz yüze görüşme tekniği kullanılarak toplanmıştır. Görüşülen kadınların tamamı araştırmaya katılmayı kabul etmiştir.

\section{Analiz}

Veriler, SPSS 20.0 paket programında analiz edilmiştir. Analizlerde, tanımlayıcı ölçütlerden frekans, yüzde; merkezi yığılım ölçütlerinden ortalama ve ortanca, sayısal verilerin değerlendirilmesinde ki-kare analizleri kullanılmıştır.

\section{BULGULAR}

Gerçekleşen doğumlardan 2 tanesi ev doğumu olup, diğer tüm doğumlar hastanede gerçekleşmiştir. Kadınların tamamı, hastaneden taburcu olduktan sonraki 45 gün içinde aile hekimi ve/veya aile sağlığ ebesinden lohusa bakımı almıştır. Kadınların, \%3,1'ine bir kez, \%57,8'ine iki kez, \%39, 1'ine ise 3 ve daha fazla lohusa bakımı verilmiştir. Kadın başına düşen ortalama lohusa bakım sayısı 2,5 $( \pm 0,8)$ 'dir.

Lohusaların \%30,3'üne hikâye, \%18,2'sine
fizik muayene, \%4,1'ine bilgilendirme/danışmanlık kısmından belirlenen parametrelerden hiçbiri verilmemiş iken; lohusaların $\% 17,7$ 'sine hikâye, \%3,3'üne fizik muayene ve \%32,9'una ise bilgilendirme/danışmanlık kısmında belirlenen tüm parametreler verilmiştir (Tablo 1).
Tüm parametreler birlikte değerlendirildiğinde, kadınların \%1,0'ine (8 kadın) parametrelerden hiçbirisi yapılmamış, \%1,2'sine (9 kadın) 16 parametrenin tamamı yapılmıştır. Lohusa başına düşen parametre ortalamas $18,5( \pm 4,1)$ ve ortancas 18 (0-16)'dir.

Tablo 2'de belirlenen parametrelerin, lohusa bakım içeriğinde yer alma durumu görülmektedir. Buna göre, lohusa bakım içeriğinde en fazla yer alan parametreler emzirme $(\% 89,6)$, demir preparatı verilmesi $(\% 81,8)$, kan basinc1 ölçümü $(\% 80,2)$ ve anne beslenmesi ile ilgili bilgi verme $(\% 76,1)$ iken, en az yer alan parametreler perine $(\% 4,7)$ ve karın $(\% 24,1)$ muayenesi, çarpıntı/nefes darlığının olup olmadığının sorulmasidır $(\% 28,0)$.

Tablo 3'de sosyodemografik özelliklerin, lohusa bakım puanı üzerine dağılımı görülmektedir. Buna göre, sosyodemografik özellikler ile lohusa bakım içeriği puanı arasında istatistiksel olarak anlamlı bir fark bulunmamıştır ( $p>0,05)$.

Tablo 4'de biyodemografik özellikler ve sağlık hizmet kullanımına ilişkin değişkenlerin lohusa bakım puanı üzerine dağılımı görülmektedir. Buna göre, biyodemografik özellikler ve sağllk hizmet kullanımına ilişkin değişkenler ile lohusa bakım içeriği puanı arasında istatistiksel olarak anlamlı bir fark bulunmamıştır ( $\mathrm{p}>0,05)$.

\section{TARTIŞMA}

Yaptığımız çalışmada, doğum yapan kadınların tümünün ilk 45 gün içinde aile hekimi ve/veya aile sağlığı ebesinden en az bir kez lohusa bakımı almış olduğu belirlenmiştir. Gelişmiş ülkelerde doğum sonrası bakım hizmeti alma oranları \%90, gelişmekte olan veya az gelişmiş ülkelerde ise bu

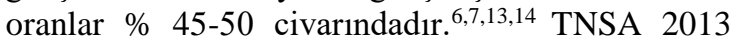
verilerine göre, ülke genelinde en az bir defa doğum sonrası bakım alan kadın oranı \%93,1 olarak bildirilirken, aynı yörede 2009 yılında benzer yöntemle yapılan bir saha çalışmasında kadınların $\% 95,2$ 'sinin lohusalık sürecinde aile hekimi ve/veya aile sağlığ 1 ebesinden en az bir defa doğum sonrası bakım hizmeti aldığı belirlenmiştir. ${ }^{10,12} \mathrm{Bu}$ açıdan bakıldığında, Türkiye'de doğum sonrası bakım hizmetlerinin kapsayıcılığının gelişmiş ülke verilerine uyum sağladığı söylenebilir.

Çalışmada, nicelik olarak yeterli doğum sonrası bakım olarak kabul edilen 3 ve üstü sayıda doğum sonrası bakım hizmeti almış kadınların oranı \%39,1'dir. TNSA 2008 verilerine göre, doğum 


\begin{tabular}{|c|c|c|c|c|c|c|}
\hline \multirow{3}{*}{$\begin{array}{l}\text { Parametrelerin yapılma } \\
\text { sayısı }\end{array}$} & \multicolumn{6}{|c|}{ Parametrelerin dâhil olduğu gruplar } \\
\hline & \multicolumn{2}{|c|}{ Hikâye } & \multicolumn{2}{|c|}{ Fizik muayene } & \multicolumn{2}{|c|}{ Bilgilendirme } \\
\hline & $\begin{array}{c}\text { Sayı } \\
(\mathrm{N}=763) \\
\end{array}$ & $\%$ & $\begin{array}{c}\text { Sayı } \\
(\mathrm{N}=763) \\
\end{array}$ & $\%$ & $\begin{array}{c}\text { Sayı } \\
(\mathrm{N}=763)\end{array}$ & $\%$ \\
\hline 0 & 231 & 30,3 & 139 & 18,2 & 31 & 4,1 \\
\hline 1 & 152 & 19,9 & 109 & 14,3 & 69 & 9,0 \\
\hline 2 & 109 & 14,3 & 149 & 19,5 & 96 & 12,6 \\
\hline 3 & 83 & 10,9 & 234 & 30,7 & 124 & 16,3 \\
\hline 4 & 53 & 6,9 & 107 & 14,0 & 192 & 25,2 \\
\hline 5 & 135 & 17,7 & 23 & 3,3 & 251 & 32,9 \\
\hline Ortalama (standart sapma) & \multicolumn{2}{|c|}{$2,0( \pm 1,8)$} & \multicolumn{2}{|c|}{$2,2( \pm 1,4)$} & \multicolumn{2}{|c|}{$3,5( \pm 1,5)$} \\
\hline
\end{tabular}

*Satır yüzdesi

Tablo 2. Lohusa bakım içeriğinde yer alan parametrelerin uygulanma sıklığı (Burdur, 2012)

\begin{tabular}{|c|c|c|c|c|}
\hline \multirow{3}{*}{ Parametreler } & \multicolumn{4}{|c|}{ Lohusa bakım içeriğinde } \\
\hline & \multicolumn{2}{|c|}{ Uygulanmış } & \multicolumn{2}{|c|}{ Uygulanmamış } \\
\hline & $\mathrm{N}=763$ & $\%$ & $\mathrm{~N}=763$ & $\%$ \\
\hline \multicolumn{5}{|l|}{ Hikâye } \\
\hline Kanama & 499 & 65,4 & 264 & 34,6 \\
\hline İdrar problemi & 291 & 38,1 & 472 & 61,9 \\
\hline Ăgr1 & 272 & 35,6 & 491 & 64,4 \\
\hline Bağırsak faaliyetleri & 230 & 30,1 & 533 & 69,9 \\
\hline Çarpıntı/nefes darlığ1 & 214 & 28,0 & 549 & 72,0 \\
\hline \multicolumn{5}{|l|}{ Fizik muayene } \\
\hline Kan basıncı ölçümü & 612 & 80,2 & 151 & 19,8 \\
\hline Nabız sayımı & 452 & 59,2 & 311 & 40,8 \\
\hline Ateş ölçümü & 378 & 49,5 & 385 & 50,5 \\
\hline Karın muayenesi & 184 & 24,1 & 579 & 75,9 \\
\hline Perine muayenesi & 36 & 4,7 & 727 & 95,3 \\
\hline \multicolumn{5}{|l|}{ Bilgilendirme } \\
\hline Emzirme & 684 & 89,6 & 79 & 10,4 \\
\hline AP yöntemleri & 576 & 75,5 & 189 & 24,5 \\
\hline Anne beslenmesi & 581 & 76,1 & 182 & 23,9 \\
\hline Meme bakımı & 450 & 59,0 & 313 & 41,0 \\
\hline Lohusa döneminde acil durumlar & 365 & 47,8 & 398 & 52,2 \\
\hline Demir preparatı & 624 & 81,8 & 139 & 18,2 \\
\hline
\end{tabular}




\begin{tabular}{|c|c|c|c|c|c|c|}
\hline \multirow{3}{*}{$\begin{array}{l}\text { Sosyodemografik } \\
\text { özellikler }\end{array}$} & \multicolumn{3}{|c|}{ Lohusa bakım içerik puanı } & \multirow{3}{*}{$\begin{array}{c}\text { Toplam } \\
\mathbf{N}=763 \\
(\%)^{* *}\end{array}$} & \multirow{3}{*}{$\chi^{2}$} & \multirow{3}{*}{$\mathbf{p}$} \\
\hline & 5 ve altı & 6-10 & 11 ve üstü & & & \\
\hline & $\begin{array}{c}\mathrm{N}=197 \\
(\%)^{*}\end{array}$ & $\begin{array}{c}\mathrm{N}=304 \\
(\%)^{*}\end{array}$ & $\begin{array}{c}\mathrm{N}=262 \\
(\%)^{*}\end{array}$ & & & \\
\hline \multicolumn{7}{|l|}{ Yerleşim yeri } \\
\hline Kir & 28,6 & 41,1 & 30,3 & $\mathbf{3 0 , 3}$ & \multirow{2}{*}{0,429} & \multirow{2}{*}{0,807} \\
\hline Kent & 34,0 & 38,0 & 28,0 & 69,7 & & \\
\hline \multicolumn{7}{|l|}{ Kadının yaşı } \\
\hline 19 yaş ve altı & 14,0 & 47,4 & 38,6 & 7,5 & \multirow{3}{*}{8,657} & \multirow{3}{*}{0,070} \\
\hline $20-34$ & 25,8 & 40,6 & 33,6 & 80,7 & & \\
\hline 35 ve üzeri & 33,3 & 30,0 & 36,7 & 11,8 & & \\
\hline \multicolumn{7}{|l|}{ Kadının eğitimi } \\
\hline 8 yil ve alt1 & 26,1 & 38,4 & 35,5 & 57,7 & \multirow{2}{*}{0,954} & \multirow{2}{*}{0,621} \\
\hline 9 yıl ve üzeri & 25,4 & 41,8 & 32,8 & 42,3 & & \\
\hline \multicolumn{7}{|l|}{ Eşinin eğitimi $* * *$} \\
\hline 8 yıl ve altı & 24,5 & 38,3 & 37,2 & 48,5 & \multirow{2}{*}{2,638} & \multirow{2}{*}{0,267} \\
\hline 9 yil ve üzeri & 26,8 & 41,6 & 31,6 & 51,5 & & \\
\hline \multicolumn{7}{|l|}{ Kadının işi } \\
\hline Çalışan & 25,8 & 45,2 & 29,0 & 12,2 & \multirow{2}{*}{1,620} & \multirow{2}{*}{0,445} \\
\hline Çalışmayan & 25,8 & 39,1 & 35,1 & 87,8 & & \\
\hline \multicolumn{7}{|l|}{ Eşinin işi ${ }^{* * *}$} \\
\hline İşsiz & 25,0 & 35,5 & 39,5 & 10,1 & \multirow{3}{*}{4,895} & \multirow{3}{*}{0,298} \\
\hline Kendi hesabına & 22,9 & 45,4 & 31,7 & 29,9 & & \\
\hline Kamu ve özel sektör & 27,6 & 37,9 & 34,6 & 60,2 & & \\
\hline \multicolumn{7}{|l|}{ Sağlık sigortası } \\
\hline Yok & 15,4 & 42,3 & 42,3 & 3,4 & \multirow{2}{*}{1,674} & \\
\hline Var & 26,2 & 39,8 & 34,1 & 96,6 & & 0,433 \\
\hline Eve giren toplam ge & & & & & & \\
\hline Yetiyor & 24,5 & 41,4 & 34,1 & 39,6 & & \\
\hline Yetmiyor & 26,7 & 38,9 & 34,3 & 43,3 & 0,636 & 0,728 \\
\hline Aile tipi & & & & & & \\
\hline Geniş aile & 25,8 & 33,3 & 0,8 & 15,7 & & \\
\hline Çekirdek aile & 25,8 & 41,1 & 33,1 & 84,3 & 3,264 & 0,196 \\
\hline Resmi nikâh & & & & & & \\
\hline Var & 25,8 & 39,5 & 34,7 & 98,2 & 2783 & 0240 \\
\hline Yok & 28,6 & 57,1 & 14,3 & 1,8 & $2, / 83$ & 0,249 \\
\hline Eş ile akrabalık & & & & & & \\
\hline Var & 27,0 & 32,4 & 40,5 & 9,7 & 2004 & 0351 \\
\hline Yok & 25,7 & 40,6 & 33,7 & 90,3 & 2,094 & 1 \\
\hline Evde yaşayan kişił & & & & & & \\
\hline 4 ve alt1 & 25,4 & 41,6 & 33,0 & 69,2 & & \\
\hline 5 ve üzeri & 26,5 & 36,3 & 37,2 & 30,8 & 2,001 & 0,368 \\
\hline Toplam* & 25,8 & 39,8 & 34,3 & 100,0 & & \\
\hline
\end{tabular}




\begin{tabular}{|c|c|c|c|c|c|c|}
\hline \multicolumn{7}{|c|}{$\begin{array}{l}\text { Tablo 4. Sağlık hizmeti kullanımı ve biyodemografik özelliklerin lohusa bakım içeriği puanı üzerine dağılımı } \\
\text { (Burdur, 2012) }\end{array}$} \\
\hline \multirow{3}{*}{$\begin{array}{l}\text { Sağlık hizmeti kullanımı ve } \\
\text { biyodemografik özellikler }\end{array}$} & \multicolumn{3}{|c|}{ Lohusa bakım içerik puanı } & \multirow[t]{2}{*}{ Toplam } & \multirow{3}{*}{$\chi^{2}$} & \multirow{3}{*}{$\mathbf{p}$} \\
\hline & 5 ve altı & 6-10 & 11 ve üstü & & & \\
\hline & $\begin{array}{c}\mathrm{N}=144 \\
(\%)^{*}\end{array}$ & $\begin{array}{l}\mathrm{N}=187 \\
(\%)^{*}\end{array}$ & $\begin{array}{l}\mathrm{N}=163 \\
(\%)^{*}\end{array}$ & $\begin{array}{l}\mathrm{N}=494 \\
(\%)^{* *}\end{array}$ & & \\
\hline \multicolumn{7}{|l|}{ Doğum yeri\# } \\
\hline Kamu hastanesi & 24,6 & 38,3 & 37,1 & 68,3 & \multirow{2}{*}{5,259} & \multirow{2}{*}{0,072} \\
\hline Özel hastane & 28,2 & 43,2 & 28,6 & 31,7 & & \\
\hline \multicolumn{7}{|l|}{ Doğum şekli } \\
\hline Normal & 25,9 & 35,8 & 38,3 & 43,5 & \multirow{2}{*}{4,984} & \multirow{2}{*}{0,083} \\
\hline Sezaryen & 25,8 & 42,9 & 31,3 & 56,5 & & \\
\hline \multicolumn{7}{|l|}{ Hastanede yatılan gün\# } \\
\hline Bir günden az & 22,2 & 33,3 & 44,4 & 2,4 & \multirow{3}{*}{2,435} & \multirow{3}{*}{0,656} \\
\hline $1-2$ gün & 26,0 & 38,6 & 35,4 & 69,1 & & \\
\hline 3 gün ve üzeri & 25,3 & 43,3 & 31,3 & 28,5 & & \\
\hline \multicolumn{7}{|l|}{ Gebelik sayısı } \\
\hline 1 & 19,7 & 43,5 & 36,8 & 35,3 & \multirow{4}{*}{8,676} & \multirow{4}{*}{0,070} \\
\hline 2 & 29,8 & 38,8 & 31,4 & 32,1 & & \\
\hline 3 & 28,5 & 36,9 & 34,5 & 32,6 & & \\
\hline Toplam* & 25,8 & 39,8 & $\mathbf{3 4 , 3}$ & 100,0 & & \\
\hline \multirow{2}{*}{\multicolumn{7}{|c|}{ Kendiliğinden düşük }} \\
\hline & & & & & & \\
\hline Var & 27,1 & 40,7 & 32,1 & 28,3 & \multirow{2}{*}{0,735} & \multirow{2}{*}{0,692} \\
\hline Yok & 29,9 & 36,7 & 33,3 & 71, & & \\
\hline \multicolumn{7}{|l|}{ İsteyerek düşük } \\
\hline Var & 33,3 & 26,7 & 40,0 & 6,1 & \multirow{2}{*}{1,723} & \multirow{2}{*}{0,423} \\
\hline Yok & 28,9 & 38,6 & 32,5 & 93,9 & & \\
\hline \multicolumn{7}{|l|}{ Ölü doğum } \\
\hline Var & 15,4 & 30,8 & 53,8 & 2,6 & \multirow{2}{*}{2,804} & \multirow{2}{*}{0,246} \\
\hline Yok & 29,5 & 38,0 & 32,4 & 97,4 & & \\
\hline \multicolumn{7}{|l|}{5 yaş altı çocuk ölümü } \\
\hline Var & 25,0 & 37,5 & 37,5 & 3,2 & \multirow{3}{*}{0,200} & \\
\hline Yok & 29,3 & 37,9 & 32,8 & 96,8 & & 0,905 \\
\hline Toplam* & 35,6 & 36,8 & 27,5 & 100,0 & & \\
\hline
\end{tabular}

*satır yüzdesi, **sütun yüzdesi, \# evde yapılan 2 doğum işleme alınmamıştır

sonras1 bakım alanların \%28'inin 2-3 defa, $\% 10,0$ 'unun ise 4 ve daha fazla doğum sonrası bakım aldığı görülmektedir. ${ }^{11} 2009$ yılında yapılan çalışmada ise, 3 ve üstü bakım alanların oranı tüm bakım alanların \%15,1'i dir. ${ }^{12} \mathrm{Bu}$ bağlamda, kapsayıcılık açısından yıllar içinde istikrarlı bir artışın olduğu söylenebilir. Öte yandan birinci basamakta verilen lohusa bakım sayıs1, hali hazırda nicel yeterlilik için öngörülen en az 3 bakımın oldukça altındadır. Ancak kadınların tamamının, en az bir defa doğum sonrası bakım hizmeti almış olması ve 3 ve üstü bakım alanlarının oranının 2009 yılına göre yaklaşık 2 kat artmış olması önemli bir bulgudur. Kapsayıcılıktaki bu artışın, birinci basamakta çalışan sağlık personelinin, gelinen süreç içinde aile hekimliği uygulamalarına daha iyi uyum sağlamasından kaynaklandığı düşünülmektedir.

Çalışmada, doğum sonrası bakım sırasında ulusal kılavuzlara göre uygulanması gerekli parametreler ele alındığında, parametrelerin uygulanma oranları oldukça düşüktür. Çalışma sonucunda, lohusaların \%30,3'üne hikâye, $\% 18,2$ 'sine fizik muayene ve \%4,1'ine bilgilendirme/danışmanlık kısmından belirlenen parametrelerden hiç birisinin verilmediği görülmüştür. Tüm parametreler birlikte değerlendirildiğinde ise, kadınların sadece 
\%1,2'sine 16 parametrenin tamamı uygulanmıştır. Lohusa başına uygulanan parametre ortalaması ise 8,5 parametredir. Bütün bu veriler 1şığında, verilen lohusa bakım içeriğinin yetersiz olduğu söylenebilir. Hâlbuki, yapılan araştırmalarda postpartum dönemde, lohusaların önemli bir kısmında kötü kokulu akıntı, şiddetli vajinal kanama, sırt ağrısı, ateş gibi istenmeyen postpartum komplikasyonlar oluştuğu belirtilmiş olup, bu komplikasyonların önlenmesinde ise temel müdahalelerden birisinin nitelikli lohusa bakımı olduğu vurgulanmıştır. ${ }^{15}$

Araştırmada, nitelik ölçütü olarak belirlenen parametreler tek, tek ele alındığında, hikâye alma bölümünde en az çarpıntı ve nefes darlığı şikayetinin sorgulandığı; fizik muayene kısmında en az yapilan uygulamanin perine muayenesi olduğu ve bilgilendirme-danışmanlık bölümünde ise, en az bilgilendirmenin lohusalık dönemindeki acil durumlarla ilgili yapıldığı belirlenmiştir. 2008 yılında yapılan TNSA çalışmasında, kan basıncı ölçümü, ateş ölçümü, emzirme, gebeliği önleyici yöntemler, gebelikte acil müdahale gerektiren durumlar, annenin beslenmesi, meme bakımı konusunda bilgi ve demir preparatı verilme oranları bu araştırmaya göre daha düşük düzeydedir. ${ }^{11}$ Yine aynı yörede 2009 yılında yapılan çalışmada, birinci basamak sağlık kurumlarında lohusaların kan basıncı, ateş ve nabız ölçümü, karın muayenesi ile lohusalara emzirme, aile planlaması, lohusalıkta acil durumlar ile ilgili bilgi verilme ve lohusaya demir preparatı verilme oranları bu araştırmaya göre daha düşük düzeylerdedir. ${ }^{12}$ Özetlemek gerekirse, lohusa bakım kalitesi zaman içerinde artma eğilimi göstermiş olsa da, rehberde öngörülen kalitenin oldukça altındadır. Bu durum sağlık personelinin iş yükünün fazla olmasından kaynaklanabileceği gibi, hizmet içi eğitimlere rağmen lohusa bakımının öneminin yeterince içselleştirilememesinden de kaynaklanabilir. Lohusa bakımı alma durumu ve lohusa bakımı alınmasını etkileyen çeşitli kültürel, ekonomik ve biyolojik faktörler ulusal ve uluslararası çalışmalarda belirlenmeye çalışılmıştır. 6,7,11 Ancak, gelinen süreçte kadınların tamamının lohusa bakımı alması, lohusa bakımını içerik açısından değerlendirmeye yöneltmiş; içeriğin kalitesini etkileyen faktörlere yönelik analitik değerlendirme yapmayı zorunlu kılar hale gelmiştir. Araştırmada, sosyodemografik, biyodemografik ve sağlık hizmet kullanımı ile ilgili bağımsız değişkenlerin lohusa bakım içerik puan kategorisi üzerine etkisi olmadığı, diğer bir deyişle çeşitli kültürel, ekonomik ve biyolojik faktörlerin lohusa bakım içeriğini etkilemediği belirlenmiştir. $\mathrm{Bu}$ durumun muhtemel nedeni sağlik hizmet sunucuları ile sağlı hizmet kullanıcıları arasında lohusa bakım içeriğine ilişkin bilginin asimetrik oluşudur. $\mathrm{Bu}$ bilgi, asimetrisi lohusa bakım içeriğinin kalitesini sağlık personelinin inisiyatifine birakmaktadir.

\section{SONUÇ}

Sonuç olarak araştırmada, kadınların tamamı en az bir defa lohusa bakımı almıştır; ancak nicel açıdan verilen hizmet yetersizdir. Öte yandan verilen lohusa bakım içeriği de, belirlenen parametreler açısından yetersizdir. Ancak aile hekimliği uygulaması sonrasında, zaman içerisinde gerek kapsayıcılık ve gerekse içerik açısından doğum sonrası bakım hizmetlerinde bir gelişme olduğu görülmektedir. İçerik ile ilgili gelişme, kapsayıcılığa göre daha geride kalmıştır. Kadınların sosyodemografik, biyodemografik ve sağlık hizmet kullanımına ilişkin özellikleri lohusa bakım içeriği üzerinde etkili değildir. Bu nedenle, verilen doğum sonrası bakım hizmetlerinin içeriğinin geliştirilmesi için aile hekimleri ve aile sağlı̆̆ elemanlarına tazeleme eğitimleri verilmesi, aralıklı saha araştırmaları ile hizmetin değerlendirilmesi doğum sonrası bakım hizmetlerinin nicelik ve içeriğini güçlendirecektir.

\section{Çalışmanın Kısıtlılıkları}

Çalışmaya alınan kadınların hepsi "Aile Hekimliği Bilgi Sistemi" ne kayıtlı ve hali hazırda birinci basamak sağlık kuruluşlarından hizmet alan kadınlardır. Herhangi bir aile hekimine kayıtlı olmayan ve birinci basamak sağlık kuruluşlarından doğum sonrası bakım hizmeti almayan kadınların olması çalışmanın önemli bir kısıtlılığıdır. Doğum sonrası bakım hizmetlerinin içeriği ile ilgili verilerin, sadece kadınlarla olan yüz yüze görüşmeye dayanması, kadınların yapılan işlemi hatırlayamaması veya bazı işlemlerin yapılmış olmasına karşın kadınların bu işlemleri bilmemesi ve bu nedenle yapılamamış gibi bildirme ihtimali çalışmanın diğer önemli bir kısıtlılığıdır.

\section{KAYNAKLAR}

1. World Health Organization: WHO Technical Consultation on Postpartum and Postnatal Care. Geneva, Switzerland: WHO Document Production Services; 2010.pp:9

2. World Health Organization: Postpartum Care of the Mother and Newborn: A Practical Guide. fourth edition. Geneva: WHO; 1998. WHO/RHT/MSM/983. pp:12

3. Hacettepe Universsity Institute of Population Studies, ICON-ISTITUT Public Sector GmbH and BNB Consuting (2006) National Maternal 
Mortality Study, 2005, Ministry of Helath, General Directoraate of Mother and Child Health and Family Planning and Delegation of European Commission to Turkey, Ankara.pp:9

4. Darmstadt GL, Bhutta ZA, Cousens S, Adam T, Walker N, de Bernis L. Lancet Neonatal Survival Steering Team: Evidence-based, costeffective interventions: how many newborn babies can we save? Lancet 2005; 365(9463):977-988.

5. MacArthur C, Winter HR, BickDE LRJ, LancashireRJ KH, Braunholtz DA, Henderson $\mathrm{C}$ et al. Redesigning postnatal care: a randomised controlled trial of protocol-based midwifery-led care focused on individual women's physical and psychological health needs. Health Technol Assess 2003; 7(37):1-98.

6. Chen L, Quiong W, van Velthoven MH, Yanfeng Z,Shuyi Z, Ye L,Wang W et al. Coverage, quality of and barriers to postnatal care in rural Hebei, China: a mixed method study. BMC Pregnancy and Childbirth 2014; 14:31.doi:10.1186/1471-2393-14-31.

7. Khanal V.Adhikari M,Karkee R,Gavidia T. Factors associated with the utilisation of postnatal care services among the mothers of Nepal: analysis of Nepal Demographic and Health Survey 2011. BMC Women's Health 2014;14:19.doi:10.1186/1472-6874-14-19

8. Hacettepe Üniversitesi Nüfus Etütleri Enstitüsü (2010) Türkiye'de Doğurganlık, Üreme Sağlı̆̆1 ve Yaşlılık, 2008 Türkiye Nüfus ve Sağlık Araştırması İleri Analiz Çalışması, Hacettepe Üniversitesi Nüfus Etütleri Enstitüsü, Sağllk Bakanlığı Ana Çocuk Sağlığı ve Aile Planlaması Genel Müdürlüğü, Başbakanlık Devlet Planlama Teşkilatı Müsteşarlığı ve TÜBİTAK, Ankara.pp:93.

9. Sağlık Bakanlığı AÇSAP Genel Müdürlüğü, Doğum Sonu Bakım Yönetim Rehberi; 2010, Ankara.

10. Hacettepe University Institute of Population Studies (2014), "2013 Turkey Demographic and Health Survey”. Hacettepe University Institute of Population Studies, T.R. Ministry of Development and TÜBITAK, Ankara, Turkey.pp:153-156.

11. Hacettepe Üniversitesi Nüfus Etütleri Enstitüsü (2009) Türkiye Nüfus ve Sağlık Araştırması, 2008. Hacettepe Üniversitesi Nüfus Etütleri Enstitüsü, Sağlık Bakanlığı Ana Çocuk Sağlığı ve Aile Planlaması Genel Müdürlüğü, Başbakanlık Devlet PlanlamaTeşkilatı Müsteşarlığı ve TÜBİTAK, Ankara, Türkiye.pp:154-159.
12. Çatak B, Sütlü S, Kılınç AS, Badıllıoğlu O, Zencir M. Burdur'da 2009 yılında doğum yapmış kadınların doğum özellikleri ve doğum sonu bakim hizmetleri. TAF Prev Med Bull 2011;10(5):1-8.

13. Dhakal S, Chapmani GN, Simkhadai P, van Teijlingen ER, Stephens J, Raja AE. Utilisation of postnatal care among rural women in Nepal.BMC Pregnancy and Childbirth 2007;7:19.

14. Chakraborty N, Islam M, Chowdhury RI, Bari W. Utilisation of postnatal carein Bangladesh: evidence from a longitudinal study. Health Soc Care Comm 2002;10(6):492-502.

15. Lomoro OA, Ehiri JE, Qian X,Tang L.Mother's perspectives on quality of postpartum care in central Shanghai, China.Int J for Qality Health Care 2002;14(5):393-402. 